\title{
OLHAR EM TRÂNSITO: IMAGENS DE SERTÃO E SERTANEJO NO DIÁRIO DE UMA EXPEDIÇÃO DE EUCLIDES DA CUNHA
}

\author{
$\underline{\text { Artur Vitor de Araújo Santana }}{ }^{1}$ \\ 1. Bolsista PROBIC/UEFS, Graduando em Licenciatura em História, Universidade Estadual de Feira de Santana, e-mail: \\ artur.vitor.santana@hotmail.com \\ 2. Orientador Valter Guimarães Soares, Departamento de Educação, Universidade Estadual de Feira de Santana, e-mail: \\ vgsoares@gmail.com \\ 3. Participante do projeto Outras Bahias: imagens do sertão na história e na literatura, Departamento de Educação, \\ Universidade Estadual de Feira de Santana, e-mail: \\ vgsoares@gmail.com
}

PALAVRAS-CHAVE: Euclides da Cunha; sertão; sertanejo.

\section{INTRODUÇÃO}

No desenrolar do processo histórico do que viria a ser o Brasil, a ideia de sertão ocupa um lugar central na imaginação social brasileira, seja enquanto elemento definidor de uma percepção dos espaços ou regiões seja como suporte de memórias e identidades. Sertão passa a ser uma categoria essencial a partir da qual se imagina o espaço, a cultura e a nação brasileira; o Brasil é algo que se pensa como constituído de litoral e sertão (Soares, 2009).

A relevância do signo sertão para pensar o Brasil ganha acento entre o final do século XIX e as primeiras décadas republicanas, em especial quando o sertanejo assume, em substituição ao indígena, a primazia enquanto perfil histórico do nacional autêntico. Euclides da Cunha já tratava de questões ligadas ao sertão e ao sertanejo, desde a escrita do artigo intitulado A nossa Vendéia, publicado no jornal $O$ Estado de S. Paulo, no qual associava a contestação dos conselheristas aos camponeses contra-revolucionários franceses da região Vendéia, ao tempo em que buscava explicar o revés militar a partir de elementos ligados ao meio físico e natural da região onde se travava o combate. Em 17 de julho de 1897, e com o mesmo título do artigo anterior, retoma retorna ao assunto, reforçando os argumentos sobre o papel jogado pela natureza na luta entre os seguidores de Antonio Conselheiro e os exércitos republicanos.

Euclides escreve sobre Canudos e os sertões de longe, sem nunca ter estado na região do conflito. De qualquer modo, em razão dos textos publicados o engenheiro militar foi convidado pelo jornal a desempenhar o papel de correspondente de guerra. Chegou a Salvador em 7 agosto de 1897, daí partindo para o sertão de Canudos em final do referido mês, viajando de trem até Queimadas, onde chegou em $1^{\circ}$ de setembro, daí seguindo a cavalo até Monte Santo (6 de setembro) e posteriormente para o arraial de Canudos (16 de setembro), onde permaneceu até o dia 3 de outubro. Neste intervalo de tempo, além de diversos telegramas, Euclides da Cunha enviou para $O$ Estado de São Paulo uma série de textos com registros e impressões da viagem (paisagem, conflito, etc), configurando-se como o Canudos: Diário de uma expedição (2003), sendo publicado em 1939, pela Livraria José Olympio Editora, sob a organização de Antônio Simões dos Reis.

Tomamos como objeto desta pesquisa investigar as imagens de sertão e de sertanejo presentes no Diário de uma expedição de Euclides da Cunha (2003). Tensionando obra, autor e a época procuramos perceber as permanências e deslocamentos da percepção euclidiana em relação ao sertão baiano-canudense e sua gente, através do confronto entre as primeiras imagens, expostas nos artigos A nossa Vendéia e aquelas que vão sendo (re)elaboradas ao longo da viagem para a região conflagrada de Canudos. É possível perceber que o olhar ativado, fruto do contato real com a paisagem física e social do norte da Bahia, opera desenquadramentos na percepção de Euclides da Cunha, embora predomine a prefiguração do momento da partida. 


\section{MATERIAL E MÉTODOS OU METODOLOGIA}

$\mathrm{Na}$ busca dos significados de sertão e de sertanejo tecidos por Euclides da Cunha nos escritos que compõem o Diário de uma expedição tomamos a obra, a um só tempo, como fonte e objeto de análise. Como as percepções humanas não são discursos neutros, entendemos que o "olhar" do engenheiro-viajante trazem régua e compasso do seu universo simbólico de origem; suas concepções de natureza, de sociedade, de política, etc., são índices que apontam para certas condições de possibilidade históricas. As molduras que limitam seu modo de ver e dizer vinculam-se aos condicionamentos culturais que informaram sua época. Neste sentido, faz-se necessário tencionar ou problematizar a relação texto-contexto.

Considerando a natureza híbrida dos textos euclidianos, geralmente situados na interface da ciência com a arte, recorro à noção de representação, defendida por Pesavento (2000), como elemento conceitual que permite articular o entrecruzamento entre o literário e o histórico. Na trilha aberta pelas novas abordagens dos estudos da cultura, considero literatura e história como representações, como versões da realidade, formas de re-criação da realidade.

Nas veredas abertas por Soares (2009), considero ainda que as representações expressam relações de força em uma dada estrutura social, remetendo para os diferentes modos como os sujeitos sociais percebem a si próprios, a sua época e ao mundo em que vivem, construindo a partir destas percepções sistemas de identidade, de crenças e de conhecimento. Nesse sentido, percorrendo as veredas da história cultural, em especial aquela aberta por Roger Chartier (2002), busco compreender como, nos discursos analisados, constroem uma realidade social sertaneja passível de ser lida.

De forma abreviada, o percurso metodológico utilizado no processo de realização do trabalho constitui-se basicamente em: 1) levantamento e leitura de bibliografia: a) teórica, com vistas a melhor explicitação do referencial teórico da pesquisa; b) sobre a trajetória do autor: memórias, biografias, etc; c) sobre a obra de Euclides, com ênfase naquelas que tomam como objeto os escritos anteriores a Os sertões; 2) revisar a literatura que tematiza o sertão, 3) análise textual da obra tomada como objeto de pesquisa; 4) escrita do relatório final e produção do resumo da SEMIC.

\section{RESULTADOS E/OU DISCUSSÃO}

Analisar os escritos de Euclides da Cunha, e por suposto as narrativas que compõem o livro Canudos: Diário de Uma Expedição (2003), implica compreender que se trata de um olhar em movimento, percebendo acima de tudo que não existe imparcialidade nas descrições da paisagem-sertão. Longe de serem discursos neutros, as paisagens são "construções do olhar humano, sempre orientado por valores, costumes, concepções políticas, éticas e estéticas, interesses econômicos e sociais, e são ditas a partir de conceitos, metáforas, tropos lingüísticos, palavras que pertencem a uma dada trama histórica, a uma dada temporalidade, a lugares de sujeito, a lugares sociais" (Albuquerque Jr, 2008, p. 205)

Considerando que descrever é um ato culturalmente criador, na medida em que a linguagem prolifera o real de sentidos e significados, no Diário Euclides da Cunha vai rabiscando uma nova geografia, instituindo o real a partir das representações imagéticas de sertão e sertanejo. Tais descrições intertextualizam escritos dos viajantes e naturalistas que o antecederam nas veredas do sertão baiano, repertório a partir do qual vai tecendo significados para o ambiente natural e humano. Também se (re)desenha ali uma imagem de Brasil. Assim, é possível compreender a geografia como uma prática social, isto é, como resultado de uma produção discursiva, e não como algo natural, que já estava dada (Soares, 2009).

A partir da análise dos diários euclidianos, é possível notar alguns deslocamentos de percepção ao longo do seu itinerário viajante, especialmente se confrontarmos com as primeiras imagens de sertão presentes nos dois artigos A nossa Vendéia, publicados no jornal O Estado de São Paulo. Euclides escreve sobre Canudos e os sertões de longe, sem nunca ter 
estado na região do conflito. Não obstante isso, segundo Santana (1998), nos artigos prefigura-se a orientação determinista que organiza sua maneira de ver e dizer, não apenas no Diário, também naquela que seria a sua mais destaca produção: Os sertões. A isso pode ser acrescentado, o repertório de imagens dos "sertões do norte" baiano apropriados dos escritos de viajantes e naturalistas que lhe antecederam na travessia por aquelas paragens, a exemplo de Martius e S. Hilaire.

O mapeamento euclidiano é feito à distância, cujas coordenadas de leitura e esquemas prévios são extraídos de um dado repertório. Deixa transparecer um regime de olhar prefigurado, em que já se sabe antes mesmo de ver. Isso se mostra com clareza em A nossa Vendeia, mas também habita o engenheiro-viajante ao longo do percurso em direção à "Meca dos jagunços" (Cunha, 2003, p.40). A título de exemplo, note-se a sua descrição da chegada a Salvador: ainda da embarcação e vislumbrado Salvador a partir da Baia de Todos os Santos, Euclides demonstra surpresa com a visão de uma cidade cujas casas vão escalando a montanha e suas "numerosas igrejas de torres esguias e altas... que recordam basílicas de Bizâncio", porém, demonstrando um saber-antes-de-ver, logo conclui: "vendo-a deste ponto... tem-se a mais perfeita ilusão de vasta e opulentíssima cidade" (Cunha, 2003, p. 30).

Porém, conforme pode se observa nos diários, as prefigurações de Euclides vão se configurando no justo impacto das cintilações do real e seu repertório prévio é colocado em choque ao deparar com o desconhecido. A partir daí, mesmo sem abandonar os esquemas préformados, percebe-se um olhar mais ativado, cada vez mais estribado no interesse em entender o novo ambiente e universo geo-sócio-cultural que se apresenta e demanda entendimento.

Já na viagem de trem até Alagoinhas, em demanda para Queimadas, Euclides da Cunha apura o olhar e chega a suas próprias análises sobre a região, ainda influenciadas pelas formulações dos viajantes, mas elucidando suas contribuições na condição de narradorobservador. Outro deslocamento do olhar é perceptível quando ele chega nas intermediações do arraial de Canudos, momento em que a paisagem natural e humana ganha mais detalhes, sentindo o escritor na pele o calor, a sede e a dificuldade inicial de se locomover diante de uma vegetação agreste. É possível perceber que Cunha reflete sobre suas predisposições consolidadas sobre o espaço-sertão, que inicialmente no artigo A nossa Vendéia descreve como "solo [...] arenoso e estéril, revestido, sobretudo na época de seca, de vegetação escassa e deprimida" (Cunha, 2003, p.121). Estas adjetivações remetem para uma imagem cristalizada de sertão, associada ao seco, ao despovoado e ao ignoto. O narrador-observador percebe beleza e delicadeza no que antes era apenas tido como "bizarro e selvagem". Aqui, é perceptível a inexistência de contato entre o engenheiro a geografia que desenha, pela expressão "época de seca", quando na verdade Cunha atravessa todo o sertão baiano em um período de estiagem, não sendo mais observável esse distanciamento quando caminha rumo a Canudos, demonstrando como o olhar em transito molda novos sentidos para os espaços.

Da mesma forma, percebe-se no decorrer dos escritos presentes no Diário de uma Expedição ambiguidades na descrição do sertanejo, sendo essas contradições indicativas de um olhar em trânsito. Inicialmente, os patrícios são "identificados à própria aspereza do solo em que nasceram, educados numa rude escola de dificuldades e perigos", refletindo naturalmente toda a inconstância e toda a rudeza do meio em que vivem" (Cunha, 2003, p. 124), mas na travessia nota-se deslizamentos de sentidos. Já na chegada a Canudos, após perceber que a a expedição de guerra sairia vitoriosa, ele afirma: "sejamos justos - há alguma coisa de grande e solene nessa coragem estóica e incoercível, no heroísmo soberano e forte dos nossos rudes patrícios transviados e cada vez mais acredito que a mais bela vitória, a conquista real consistirá no incorporá-los amanhã, em breve, definitivamente, à nossa existência política" (Cunha, 2003, p. 108). Dessa forma, mesmo (re)desenhando os sertanejos, definindo como "fortes" e "corajosos", que seriam um desvio do olhar da predisposição 
inicial dos sujeitos, ainda mantém uma imagem negativa, porém Cunha busca anexar os "rudes patrícios" ao projeto de nação republicana que o jornalista se predispunha a construir.

\section{CONSIDERAÇÕES FINAIS}

Percebemos que existe um deslocamento nas percepções de sertão e sertanejo nos escritos Canudos: Diário de uma Espedição (2003), desde a publicação do artigo A nossa Vendéia até os primeiros contatos com a região de Canudos. Tais alterações só são possíveis pelo fato que o olhar em trânsito do correspondente de guerra possibilitou a construção de imagens que não cabiam no enquadramento realizado previamente antes da expedição pelo sertão baiano. Esse novo olhar, embora muito pouco empático e aberto á diferença, já é mais compreensivo diante da situação que se encontravam os sertanejos que fundaram a comunidade de Canudos, ficando aterrorizado com a forma como se deu o massacre

Euclides da Cunha marca uma grande virada para uma leitura social do Brasil, já que busca anexar os sertanejos, mesmo diante de sua "incivilidade", ao projeto político de nação republicana que se pretendia construir a partir dos últimos anos do século XIX e o início do século XX, abraçando os mestiços dos sertões como autênticos brasileiros.

\section{REFERÊNCIAS}

ALBUQUERQUE JÚNIOR, Durval Muniz de. A invenção do nordeste e outras artes. São Paulo: Cortez, 2011.

AMADO, Janaína. Região, sertão, nação. Estudos Históricos, Rio de Janeiro, v. 8, n. 15, p. 145-151, 1995.

CHARTIER, Roger. “Introdução”. In: A História Cultural: Entre práticas e representações $2^{a}$ Ed.- Portugal:DIFEL 82, 2002.

O mundo como representação. In: Estudos Avançados, no 11, v. 5, 1991, p. 173-191.

CUNHA, Euclides. Canudos: Diário de uma expedição. São Paulo: Editora Martin Claret, 2003.

NICOLAZZI, Fernando. "O narrador e o viajante: Notas sobre a retórica do olhar em Os Sertões”. In: História da Historiografia, n 2, mar/ 2009.

PESAVENTO, Sandra Jatahy. Literatura, história e identidade nacional. Vidya. Santa Maria, v. jan-ju, p. 9-27, 2000.

SANTANA, José Carlos Barreto de. Geologia e metáforas geológicas em Os sertões. Hist. cienc. saude-Manguinhos [online]. 1998, vol.5, suppl. [citado 2015-04-05], pp. 117-131

SOARES, Valter Guimarães. História \& Literatura: é possível sambar? Praxis, Salvador, v. 03, p. 35-45, 2006.

Cartografia da Saudade: Eurico Alves e a invenção da Bahia Sertaneja. Salvador: EDUFBA; Feira de Santana: UEFS Editora, 2009.

Literatura de viagem: a mirada de Spix e Martius sobre o sertão baiano. In: VIII Encontro Estadual de História - Anpuh-Ba, Ilhéus, 2012. 